\title{
EFFECT OF LUTING CEMENT TO PUSH-OUT BOND STRENGTH OF FIBRE REINFORCED POST
}

N.A. Yahya, J.L. Lui, K.W.A. Chong, C.M. Lim, N.H.

Abu Kasim, Z. Radzi. Effect of luting cement to pushout bond strength of fibre reinforced post. Annal Dent Univ Malaya 2008; 15(1): 11-19.

\section{ABSTRACT}

The objective of this study was to investigate the effect of various luting cement systems on bond strength of fibre-reinforced posts to root canal dentine. 40 extracted single rooted sound premolar teeth were root filled, decoronated and randomly divided into four groups. Fibre posts, AesthetiPlus $^{\text {TM }}$ (Bisco,Inc. Schaumburg, IL, USA) were cemented using four luting cements: Group A (control): Elite $100^{\circledR}$ Zinc phosphate (GC Corp, Japan), Group B: Calibra ${ }^{\mathrm{TM}}$ Esthetic Resin Cement (Dentsply Caulk, USA), Group C: RelyX ARC Adhesive Resin (3M ESPE), Group D: RelyX Unicem Aplicap (3M ESPE). Each root was sliced into 2 discs representing the coronal and middle portions of the root canal giving rise to 20 specimens per group. Bond strength was determined using push-out tests and data was analyzed using SPSS version 14.0. The mean bond strength of Group A to Aestheti-Plus ${ }^{\mathrm{TM}}$ post was $7.71 \mathrm{MPa}( \pm 2.51)$ and Group B was $5.69 \mathrm{MPa}( \pm 3.23)$. Group C exhibited the lowest mean bond strength, 4.29 $\mathrm{MPa}( \pm 3.53)$ while the highest bond strength was obtained from Group D, $7.98 \mathrm{MPa}( \pm 2.61)$. One way ANOVA showed significant interaction between all groups $(\mathrm{p}=.001)$. Post-hoc Bonferroni test revealed that bond strength of Group $\mathrm{C}$ was significantly lower compared to Group A $(\mathrm{p}=.008)$ and D $(\mathrm{p}=.004)$. In conclusion, the mean bond strength of AesthetiPlus $^{\mathrm{TM}}$ post to root canal dentine was highest when cemented with RelyX Unicem resin cement followed by Elite $100^{\circledR}$ zinc phosphate cement, Calibra and RelyX ARC resin cements. However, the bond strengths of Calibra and RelyX Unicem resin cements were not significantly different from Elite $100^{\circledR}$ zinc phosphate cement.

Key words: push-out bond strength; fibre post

\section{INTRODUCTION}

Endodontic posts have been shown to improve the retention of foundation core restorations for endodontically treated teeth which have significant loss of coronal tooth structure. It has also been demonstrated that these posts do not strengthen a root (1). Most clinical failures involving

Original Article

N.A. Yahya ${ }^{1}$, J.L. Lui ${ }^{1}$, K.W.A. Chong ${ }^{2}$, C.M. Lim², N.H. Abu Kasim ${ }^{1}$, Z. Radzi ${ }^{3}$

\section{${ }^{1}$ Department of Conservative Dentistry \\ 2 Undergraduate Students \\ ${ }^{3}$ Department of Children's Dentistry and Orthodontics}

Faculty of Dentistry

University of Malaya

50603 Kuala Lumpur

Email: nazlin(um.edu.m,

Corresponding author: Dr Noor Azlin Yahya

endodontically-treated teeth reconstructed with posts are due to cementation failure of the posts; with root fractures being the most serious type of failure (24). In situations in where all-ceramic restorations are used for restoring maxillary anterior teeth, metal posts may result in unfavourable aesthetic results, such as grey discolouration of translucent allceramic crowns and the surrounding gingiva (5). Moreover, corrosive reactions with prefabricated posts made from certain metal alloys can cause complications involving the surrounding tissues and oral environment, including metallic taste, oral burning, sensitization, oral pain and other reactions $(6,7)$. Various tooth-coloured posts such as fibrereinforced posts are available and provide some advantages when restoring endodontically-treated teeth $(8,9)$.

Different resin luting cements and their corresponding bonding systems have been proposed for the cementation of tooth-coloured posts. The composition of these resin luting cements and their mode of polymerization may influence their properties $(10,11)$. Different viscosities of the luting cement (12) and the monomer composition (13) have also resulted in differences in adhesive properties of the resin luting cements. Several in vitro studies reported controversial results regarding bond strengths of different luting cements to endodontic posts and root canal dentine (14-20).

Bond strength between post and tooth has been measured through conventional tensile testing on external root dentine or on the post space surface with pull-out and push-out methods. The latter has the benefit of being more clinically relevant (21).

The present investigation evaluated the effect of various luting cement systems on bond strength of fibre-reinforced posts to root canal dentine. The null hypothesis was that the bond strength of fibre- 
reinforced posts to root canal dentine was not affected by luting cement systems.

\section{MATERIALS AND METHODS}

In this study, three resin luting cement systems and one conventional cement were evaluated as illustrated in Table 1. Zinc phosphate cement (Elite $100^{\circledR}$, GC Corp, Japan) was used as the control group.

Forty sound single rooted extracted premolar teeth were collected. The clinical crowns were removed using a separating disc mounted on a slow speed handpiece under constant water spray, leaving the root of approximately $14 \mathrm{~mm}$ in length. Extirpation of pulp tissues was done using a barbed broach (Dentsply-Maillefer, Switzerland). The canals were prepared chemomechanically using step back technique. The master apical file was standardized to size 35 in all canals. The canals were then obturated with gutta-percha cones (Dentsply Asia, Hong Kong) and a eugenol-free sealer, Sealapex (SybronEndo, CA) using the lateral condensation technique. The master cone was coated with cement and inserted to the working length, a finger spreader (Kerr) was inserted into the canal about $1 \mathrm{~mm}$ back from the working length, and lateral compaction was performed with non-standardized gutta-percha cones until the canal was obturated. Radiographs were taken after obturation to ensure that the quality of the root filling was satisfactory. All the specimens were then stored in distilled water for 24 hours at $37^{\circ} \mathrm{C}$ and $100 \%$ humidity in an incubator to ensure complete setting of the sealer before being restored with Aestheti-Plus ${ }^{\mathrm{TM}}$ post (Bisco Dental Products Schaumburg, IL USA), a quartz fibre and epoxy composite posts.
Post space was prepared according to the manufacturer's instruction. Corresponding drills (Fig. 1) were provided with the selected post size \#2 Aestheti-Plus ${ }^{\circledR}$ post. The diameter of each post was $1.8 \mathrm{~mm}$ coronally and $1.2 \mathrm{~mm}$ apically (Fig. 2). The depth of each post space was standardized to $9 \mathrm{~mm}$ from the sectioned root face (Fig. 3).

The specimens were distributed randomly into 4 groups of 10 teeth each. The posts in Group A (Control) was cemented with Elite $100^{\circledR}$ Zinc Phosphate Cement, Group B with Calibra ${ }^{\mathrm{TM}}$ Esthetic Resin Cement, Group C with RelyX ${ }^{\mathrm{TM}}$ ARC Adhesive Resin Cement and Group D with RelyX ${ }^{\mathrm{TM}}$ Unicem Aplicap Resin Cement. The posts were cemented by a single operator adhering strictly to each manufacturer's instructions. Finger pressure was maintained on the post till the cement set. Excess cement was removed and each specimen was cleaned with a moist cotton roll.

All the specimens were mounted in epoxy resin (Mirapox, Miracon, Malaysia) using cylindrical plastic moulds and were allowed to set for 24 hours. Specimens were cross-sectioned, $3 \mathrm{~mm}$ in thickness into coronal and middle portion (Fig. 4) using a sectioning machine (Isomet ${ }^{\mathrm{TM}} / 2000$ Precision saw, Beuhler) giving rise to 20 specimens per group. The speed of sectioning ranged from 250-300 cycles per minute under a coolant spray and applied load of $260 \mathrm{~N}$.

Push-out test was used to evaluate the bond strength between luting cements and posts. The sectioned specimens were mounted on a custom made jig (Fig. 5) and the post was loaded with a 1.5 $\mathrm{mm}$ diameter cylindrical plunger. The plunger tip was sized and positioned to touch only the post without stressing the surrounding post space walls (Fig. 6). The load was applied on the apical aspect

Table 1. Luting cements and corresponding adhesive systems used in the study

\begin{tabular}{|c|c|c|c|c|c|}
\hline $\begin{array}{l}\text { Group } \\
\text { (Number of } \\
\text { specimens) }\end{array}$ & $\begin{array}{l}\text { Luting } \\
\text { Cement }\end{array}$ & $\begin{array}{l}\text { Bonding } \\
\text { Agent }\end{array}$ & Manufacturer & $\begin{array}{l}\text { Classification } \\
\text { of Adhesive } \\
\text { System }\end{array}$ & Main Constituents \\
\hline$A(20)$ & $\begin{array}{l}\text { Elite } 100^{\circledR} \\
\text { Zinc phosphate }\end{array}$ & - & GC, Japan & $\begin{array}{l}\text { Conventional } \\
\text { luting cement }\end{array}$ & $\begin{array}{l}\text { Powder: Zinc oxide, magnesium oxide } \\
\text { Liquid: Orthophosphoric acid }\end{array}$ \\
\hline B (20) & $\begin{array}{l}\text { Calibra }^{\mathrm{TM}} \\
\text { Esthetic } \\
\text { Resin } \\
\text { Cement }\end{array}$ & $\begin{array}{l}\text { Prime \& } \\
\text { Bond NT }\end{array}$ & $\begin{array}{l}\text { Dentsply } \\
\text { Caulk, USA }\end{array}$ & $\begin{array}{l}2 \text { steps } \\
\text { total-etch }\end{array}$ & $\begin{array}{l}\text { Base paste: Dimethacrylate resins, } \\
\text { camphorquinone, stabilizers, barium } \\
\text { boron fluoroalumino- silicate glass, } \\
\text { hydrophobic amorphous fumed silica, } \\
\text { titanium oxide, pigments.Catalyst } \\
\text { paste: Dimethacrylate resins, } \\
\text { stabilizers, glass fillers, fumed silica, } \\
\text { benzoyl peroxide }\end{array}$ \\
\hline$C(20)$ & $\begin{array}{l}\text { RelyX } X^{\mathrm{TM}} \text { ARC } \\
\text { Adhesive Resin }\end{array}$ & $\begin{array}{l}\text { Single } \\
\text { Bond }\end{array}$ & $\begin{array}{l}\text { 3M ESPE, } \\
\text { St Paul, Minn }\end{array}$ & $\begin{array}{l}2 \text { steps } \\
\text { total-etch }\end{array}$ & $\begin{array}{l}\text { BISGMA, TEGDMA, silica, zirconium } \\
\text { glass }(67.5 \% \text { wt) }\end{array}$ \\
\hline$D(20)$ & $\begin{array}{l}\text { RelyX }{ }^{\mathrm{TM}} \\
\text { Unicem Aplicap }\end{array}$ & - & $\begin{array}{l}\text { 3M ESPE, } \\
\text { St Paul, Minn }\end{array}$ & $\begin{array}{l}\text { Self-adhesive } \\
\text { resin cement }\end{array}$ & $\begin{array}{l}\text { Silica, glass, calcium hydroxide, } \\
\text { methacrylate, phosphoric ester, } \\
\text { dimethacrylate, acetate }\end{array}$ \\
\hline
\end{tabular}




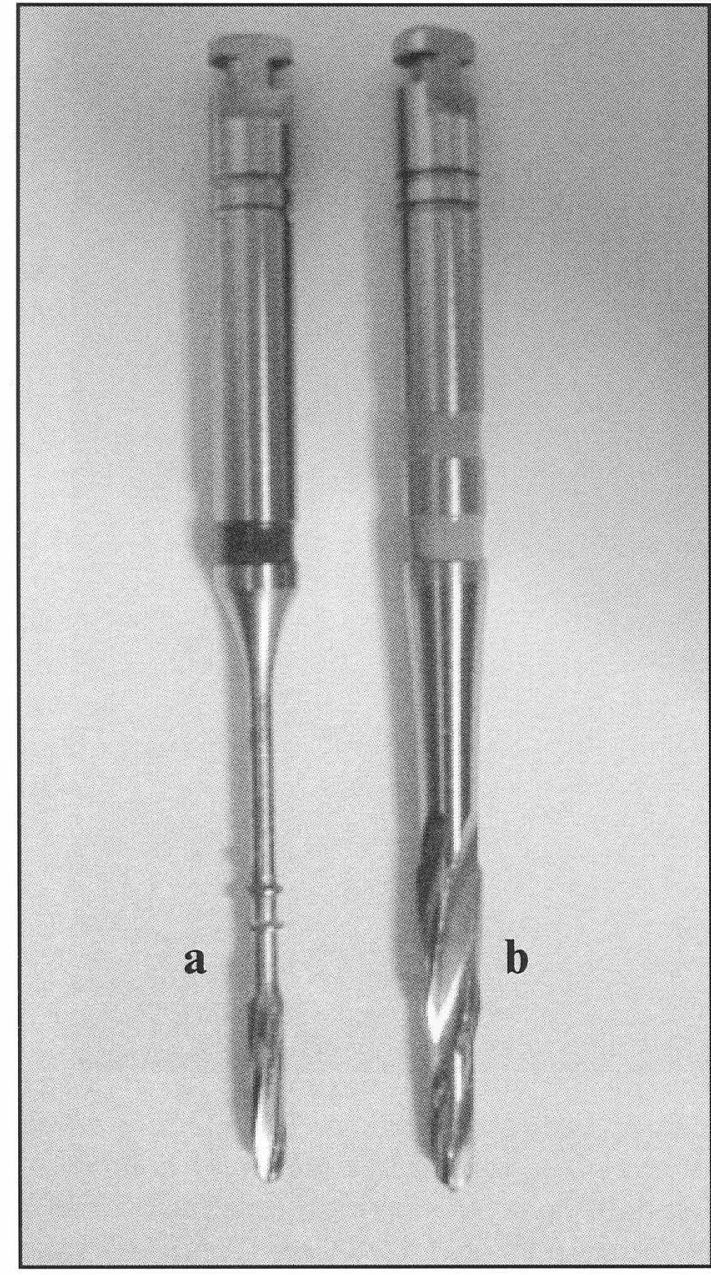

Figure 1: Pre-shaping (a) and Finishing (b) drills.

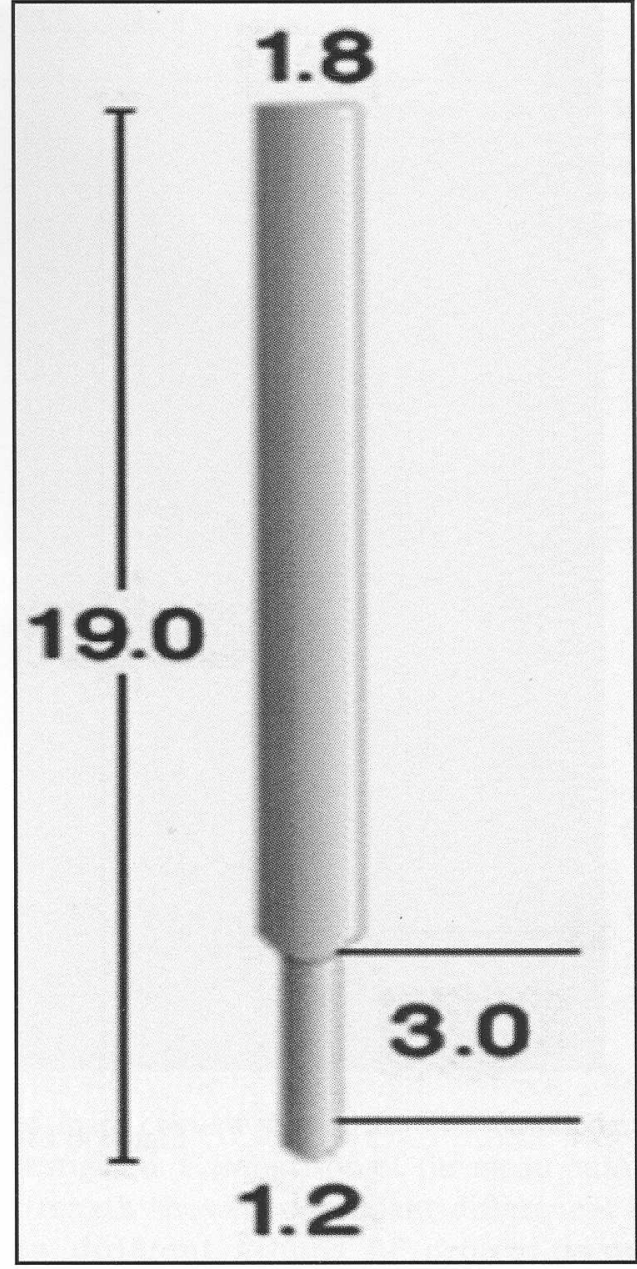

Figure 2: Schematic diagram of the Aestheti-Plus $^{\mathrm{TM}}$ post $(\mathrm{mm})$

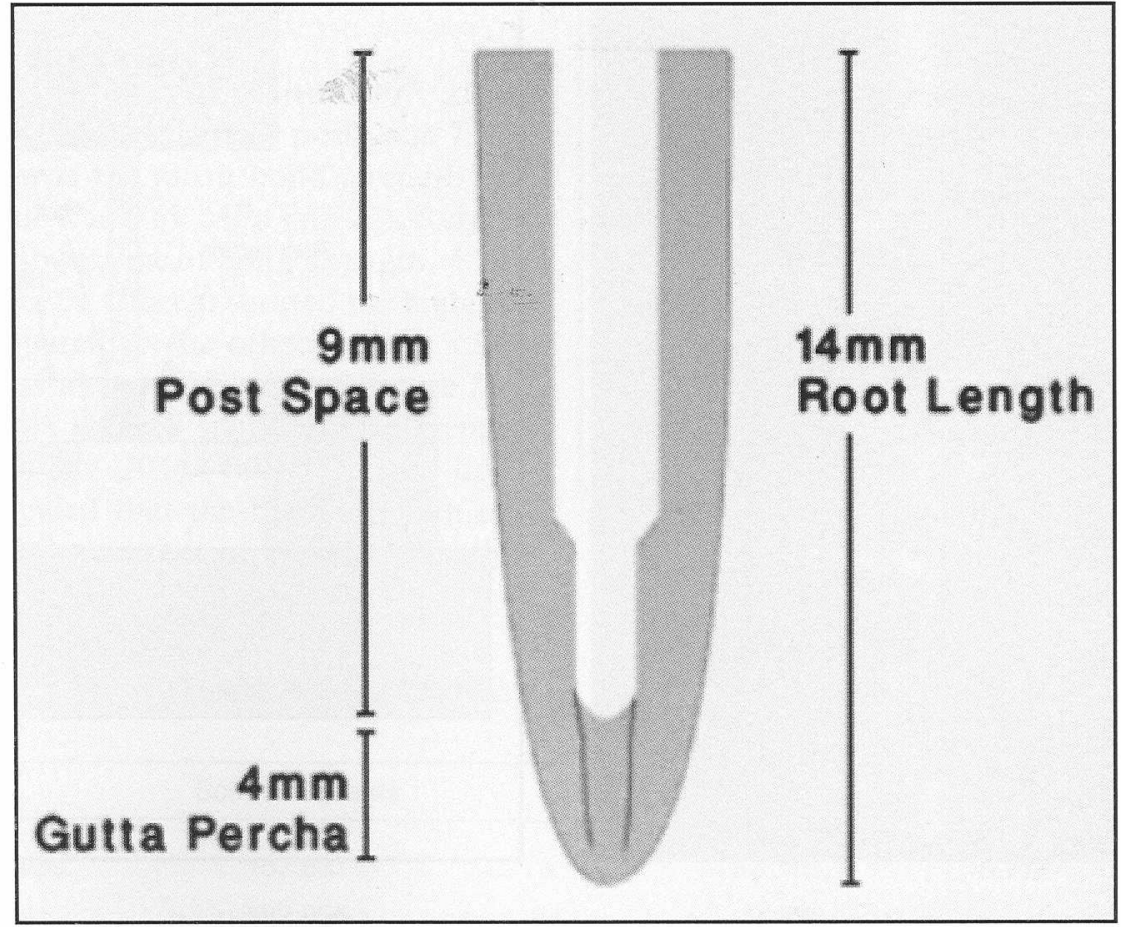

Figure 3: Schematic diagram showing the depth of the post space. 


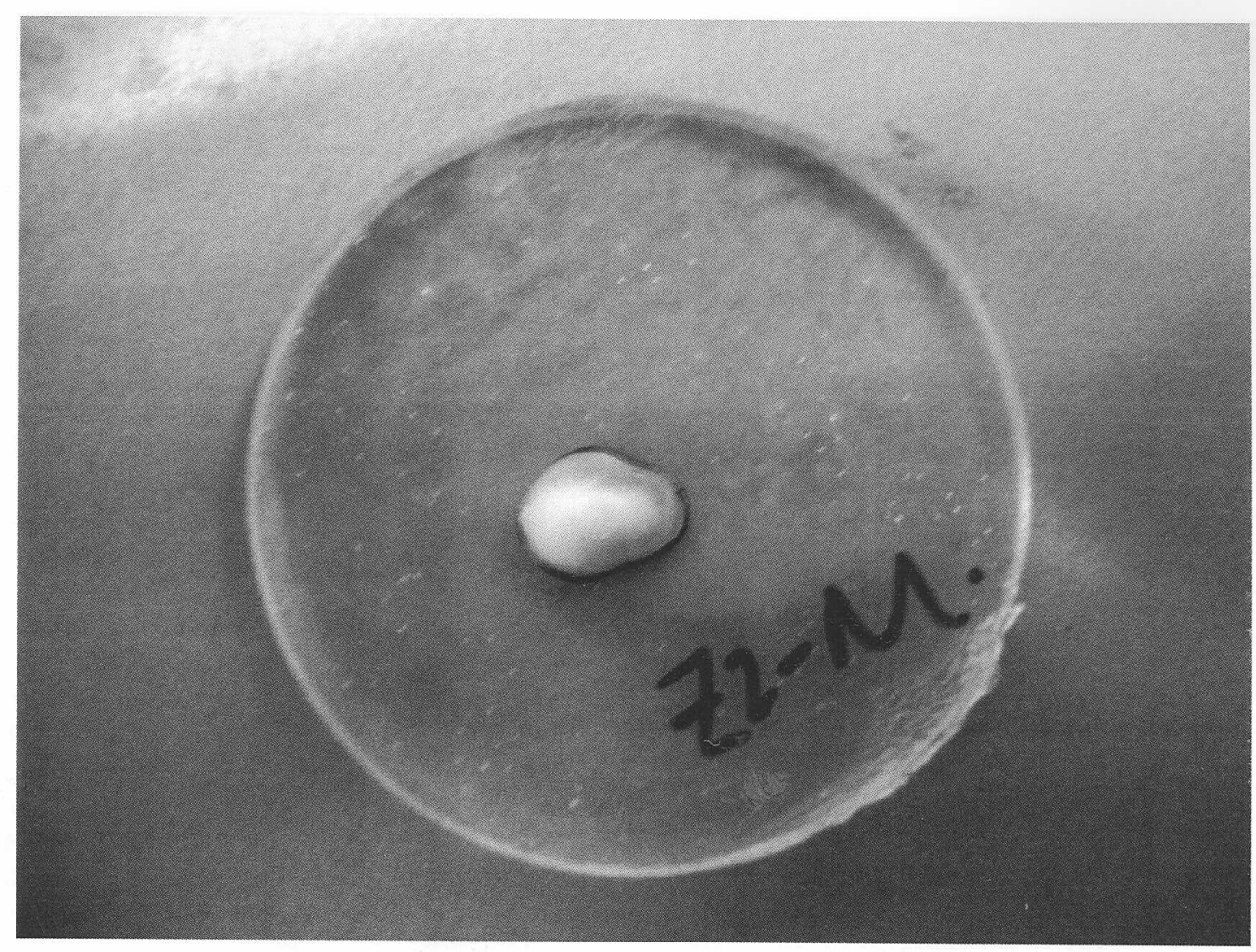

Figure 4: Close-up view of sliced specimen.

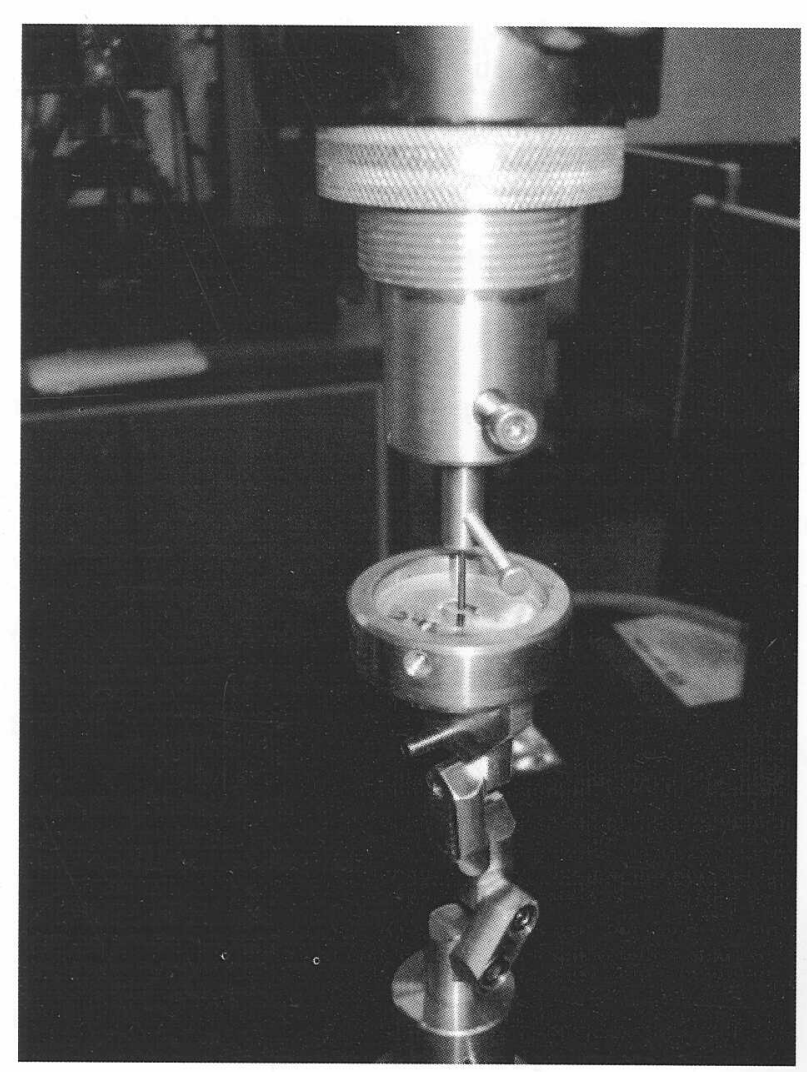

Figure 5: Specimen placed into the custom-made jig for push-out test.

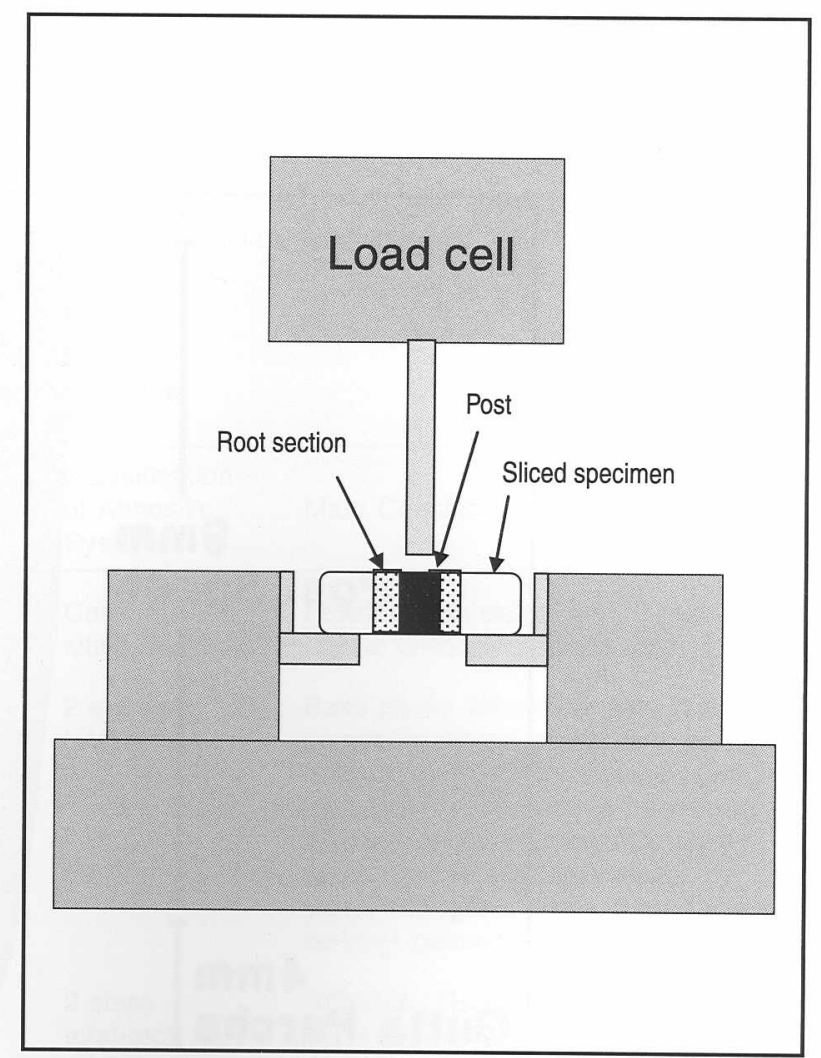

Figure 6: Schematic diagram of the push-out test. 
Table 2. Mean bond strength of 4 types of luting cement systems

\begin{tabular}{lccccc}
\hline GROUP: MATERIAL & Mean & Std. Deviation & Std. Error & \multicolumn{2}{c}{$95 \%$ Confidence Interval for Mean } \\
\cline { 5 - 6 } & & & & Lower Bound & Upper Bound \\
\hline A: Elite & 7.71 & 2.51 & 0.61 & 6.41 & 9.00 \\
B: Calibra & 5.69 & 3.23 & 0.78 & 4.02 & 7.35 \\
C: RelyX ARC & 4.29 & 3.53 & 0.83 & 2.53 & 6.05 \\
D: RelyX Unicem & 7.98 & 2.61 & 0.65 & 6.59 & 9.37 \\
\hline
\end{tabular}

of the sectioned specimens in an apical-coronal direction so as to push the post towards the larger part of the root slice. Loading was performed on a universal testing machine at a crosshead speed of 1.0 $\mathrm{mm} / \mathrm{min}$ until bond failure occurred. The force $(\mathrm{N})$ required to debond the post was recorded. The bond strength in $\mathrm{MPa}$, was calculated from the following formula:

$$
\frac{\mathrm{N}}{2 \pi \mathrm{rh}}
$$

where $\pi=$ constant $3.14, \mathrm{r}=$ post radius, $\mathrm{h}=$ thickness of the slice in $\mathrm{mm}$.

The data collected from the study was analyzed using the Statistical Packages for Social Sciences (SPSS) version 14.0. The significance of the test was set at 95\% Confidence Interval. One-way Analysis of Variance (ANOVA) and Post Hoc Bonferroni test were carried out to analyze the effects of various luting cement systems on bond strength of AesthetiPlus $^{\mathrm{TM}}$ posts to root canal dentine.

\section{RESULTS}

The mean bond strength of Elite $100^{\circledR}$ zinc phosphate cement to Aestheti-Plus ${ }^{\mathrm{TM}}$ posts was 7.71 $\mathrm{MPa}( \pm 2.51)$. Whereas the mean bond strength of Calibra resin cement was $5.69 \mathrm{MPa}( \pm 3.23)$. RelyX ARC exhibited the lowest mean bond strength, 4.29 $\mathrm{MPa}( \pm 3.53)$ and RelyX Unicem showed the highest bond strength compared to the other groups, 7.98 $\mathrm{MPa}( \pm 2.61)$ as illustrated in Table 2 and Figure 7.

One way ANOVA showed significant difference between all groups $(p=.001)$ (Table 3$)$. Post-hoc Bonferroni test revealed that the bond strength of Group C, RelyX ARC resin cement, was significantly lower compared to the control group, Elite $100^{\circledR}$ zinc phosphate cement $(p=.008)$ and Group $D$, RelyX Unicem Aplicap ( $\mathrm{p}=.004)$ (Table 4).

\section{DISCUSSION}

endodontically treated teeth is mainly advantageous for preventing root fractures (8). However, for a successful build-up of a subsequent resin core, it is necessary to establish a strong bond between resin and post as well as resin and dentine. If bonding at these interfaces is poor, debonding and / or fracture of the post and core will occur.

In this study, the bond strength between different types of resin cement system to root canal dentine was investigated. Comparison of the mean push-out bond strength showed significant differences exist between different groups of cement systems. Therefore the null hypothesis of the present study is rejected. The bond strength of Aestheti-Plus ${ }^{\mathrm{rM}}$ posts

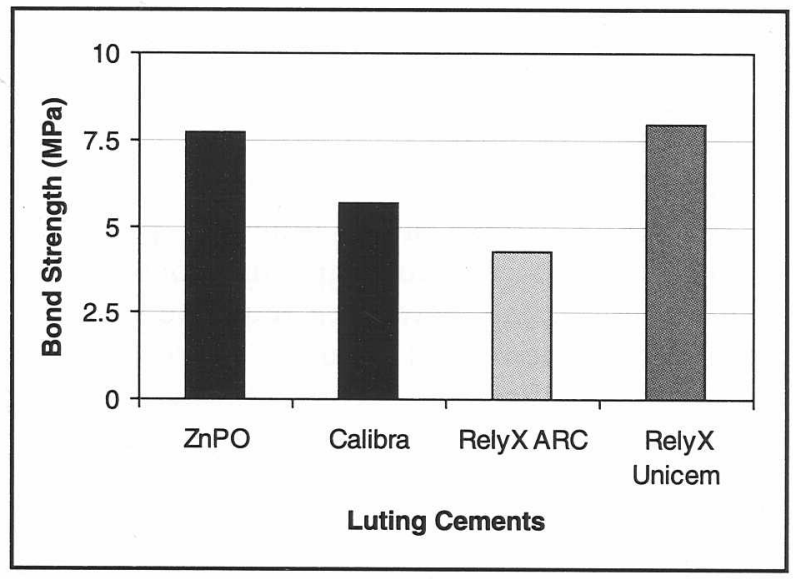

Figure 7: Mean bond strength (MPa) of 4 types of luting cement systems.

Table 3. One way ANOVA: Bond strength of luting cements

\begin{tabular}{lccccc}
\hline & Sum of Squares & df & Mean Square & F & Sig. \\
\hline Between Groups & 157.831 & 3 & 52.610 & 5.776 & .001 \\
Within Groups & 582.956 & 64 & 9.109 & & \\
Total & 740.787 & 67 & & & \\
\hline
\end{tabular}


Table 4. Post Hoc Bonferroni test: Bond strength of luting cements

\begin{tabular}{lcccccc}
\hline (I) Group & (J) Group & $\begin{array}{c}\text { Mean Difference } \\
(\mathrm{I}-\mathrm{J})\end{array}$ & Std. Error & Sig. & \multicolumn{2}{c}{$95 \%$ Confidence Interval } \\
\cline { 5 - 7 } & & & & Lower Bound & Upper Bound \\
\hline A: Elite(Control) & B & 2.01941 & 1.03519 & .333 & -.7991 & 4.8380 \\
& C & $3.41768\left(^{*}\right)$ & 1.02071 & .008 & .6386 & 6.1968 \\
& D & -.27551 & 1.05124 & 1.000 & -3.1378 & 2.5867 \\
B:Calibra & A & -2.01941 & 1.03519 & .333 & -4. und8380 & .7991 \\
& C & 1.39827 & 1.02071 & 1.000 & -1.3809 & 4.1774 \\
C:RelyX ARC & D & -2.29493 & 1.05124 & .196 & -5.1572 & .5673 \\
& A & $-3.41768\left(^{*}\right)$ & 1.02071 & .008 & -6.1968 & -.6386 \\
& B & -1.39827 & 1.02071 & 1.000 & -4.1774 & 1.3809 \\
D: RelyX Unicem & D & $-3.69319\left(^{*}\right)$ & 1.03698 & .004 & -6.5166 & -.8698 \\
& A & .27551 & 1.05124 & 1.000 & -2.5867 & 3.1378 \\
& B & 2.29493 & 1.05124 & .196 & -.5673 & 5.1572 \\
\hline
\end{tabular}

- The mean difference is significant at the .05 level.

to root canal dentine was affected by the various luting cement systems.

According to Ferrari et al (22) the differences in the results may be due to factors such as the handling characteristics of the adhesive system, root anatomy, tooth position, presence of coronal residual tissues; light curing technique, experience and skill of the operators. In addition, the difference in film thickness of the luting cements may contribute to the present results although all possible measures had been taken for standardization in post space preparation.

In this study, Calibra and RelyX ARC resin cement have almost similar results in bond strength and gave lower bond strength values compared to the other two groups of cements. Both Calibra and RelyX ARC were 2-step total-etch dual-cured resin cements. They need pretreatment such as application of etchant, primer and adhesive prior to cementation. According to Swartz and Robbins (23), resin luting cements have been found to be more technique sensitive and required more steps as compared to other conventional luting cements. Predictable delivery of etchants and adhesive materials deep into the post space can be very challenging (24). Inability to produce a good etching surface of the intra-canal dentine wall in addition to limited access for the adhesive materials to reach the most apical part of the post space can affect the bond strength of such cements.

Calibra and RelyX ARC resin cement required hand mixing prior to application of the cement. According to Kingsford-Smith and Martin (25), hand mixing produces a lack of consistency in the physical properties of set materials. Porosities might also be induced by incorporation of air bubbles into the materials; the requirement of mixing the base and catalyst pastes of the resin luting cements would incorporate air thus leading to void formation.
However, for RelyX Unicem, a one step self-etch dual-cured resin cement, no pretreatment prior to cementation was required and mixing was carried out using an electronic mixing device, rather than by hand.

According to Marco and co-workers (26), RelyX Unicem self-adhesive resin cement exhibited sealing properties that were better than Calibra resin cement when they were used to cement fibre posts in endodontically treated teeth. The RelyX Unicem presented very low amount of bubbles and voids within the cement layer as compared to Calibra. It was suggested that this may be due to the ability of the new RelyX Unicem Aplicap elongation tip to deliver the luting cement completely into the canal. Moreover, the technique of this self-adhesive resin cement is less sensitive as compared to the 2-step total-etch resin cements. A study done by Luca et al., (27) showed that the injection technique used to deliver the luting cement into the canal produced less air bubbles and voids in all the samples.

Calibra used Prime \& Bond NTтM Dual Cure adhesive, which contained a dual cure activator whereas RelyX ARC resin cement used Single Bond adhesive that was activated only by visible light curing. It had been shown that light penetration was limited inside the root canal, even with the use of translucent posts (22).

A study done by Luis et al., (28) demonstrated that RelyX ARC resin cement depended on light activation to reach the proper degree of conversion. To ensure that the luting cement achieve maximum physical properties, the conversion rate should be as high as possible.

Other than the adhesive system, the delivery system itself of both the adhesive and luting cement into the root canal was an important factor that could affect bond strength. In this study, both Calibra and RelyX ARC resin cement system 
involved the use of bristle brushes supplied by the respective manufacturers for adhesive application. It had been speculated that primer/adhesive application with standard brush tips that were supplied together with the respective adhesive systems probably resulted in solution accumulation into the post-space at the apical region; thus limiting solvent volatilization and this could interfere with the polymerization process (29). According to Leary (30), it is important to avoid adhesive accumulation in the apical third of the root canal because the restricted access to this area can create additional difficulty for the light activation process; thus making this region predisposed to post displacement prior to complete cement setting. The inappropriate shape and dimension of disposable bristle brush tips were also known to restrict the homogenous application of the adhesive solution into constricted root apical areas (31).

In this present study, the relatively high push-out bond strength obtained in zinc phosphate specimens was unexpected. Traditionally, it was thought that resin cements would have higher bond strength when compared to zinc phosphate. However, in this study, the push-out bond strength of the zinc phosphate group was higher compared to Calibra and RelyX ARC groups. Its bond strength was only slightly inferior to RelyX Unicem resin cement and also their difference was not significant. These results were supported by an evaluation of the interfacial pushout bond strength of fibre posts by Fernanda and co-workers (32). In their study, zinc phosphate produced higher push-out bond strength when compared to resin cements used in their study. The relatively high interfacial strength of the zinc phosphate cement could be explained by the composition of the cement itself which contributed to the frictional retention (33). However, it must be pointed out that the clinical use of zinc phosphate cement, as a luting material for fibre posts, needs further investigation because other studies had shown that this cement had low potential for sealing the root canal wall and lack of adhesion to the surface of the post (34).

Recommendations for further study:

1. To conduct a similar study to include more varieties of luting cement systems so as to provide a more representative result.

2. To conduct a similar study to analyse and determine features at the microscopic level contributing to bond strength using the Scanning Electron Microscope (SEM).

3. To conduct a similar study to compare the different types of adhesives, their delivery systems and the outcome to bond strength.

4. To conduct a randomize clinical trial to investigate the survival rate of different types of fibre-reinforced post cemented with various types of luting cement.

\section{CONCLUSIONS}

The mean bond strength of Aestheti-Plus ${ }^{\mathrm{TM}}$ post to root canal dentine was highest in RelyX Unicem resin cement followed by Elite $100^{\circledR}$ zinc phosphate cement, Calibra and RelyX ARC resin cement. However, the bond strengths of Calibra and RelyX Unicem resin cements were not significantly different from Elite $100^{\circledR}$ zinc phosphate cement. Rely X ARC showed significantly lower bond strength compared to Rely X Unicem and Elite $100^{\circledR}$ zinc phosphate cement.

\section{ACKNOWLEDGEMENT}

The authors thank Dr Marhazlinda Jamaludin for statistical analysis and staff of the biomaterials research laboratory, Faculty of Dentistry and Faculty of Engineering for their technical assistance.

\section{REFERENCES}

1. Sorensen JA, Engelman MJ. Effect of post adaptation on fracture resistance of endodontically treated teeth. J Prosthet Dent 1990; 64: 419-24.

2. Axelsson P, Lindhe J, Nystrom B. On the prevention of caries and periodontal disease. Results of a 15-year longitudinal study in adults. J Clin Perio 1991; 18: 182-9.

3. Testori T, Badino M, Castagnola M. Vertical root fractures in endodontically treated teeth: a clinical survey of 36 cases. J Endodon 1993; 19: 87-91.

4. Bergman B, Lundquist P, Sjogren U, Sunquist G. Restorative and endodontic results after treatment with cast posts and cores. J Prosthet Dent 1989; 61: 10-5.

5. Meyenberg KH, Luthy H, Schaerer P. Zirconia posts: a new all-ceramic concept for non vital abutment teeth. J Esthet Dent 1995; 7: 73-80.

6. Hayashi Y, Nakamura S. Clinical application of energy dispersive $\mathrm{x}$-ray microanalysis for nondestructively confirming dental metal allergens. Oral Surg Oral Med Oral Patho 1994; 77: 623-6.

7. Kedici SP, Aksut AA, Kilicarslan MA, Bayramoglu G, Gokdemir K. Corrosion behaviour of dental metals and alloys in different media. J Oral Rehabil 1998; 25: 800-8. 
8. Batemen G, Ricketts DN, Saunders WP. Fibrebased post systems: a review. Br Dent J 2003; 195: 43-8.

9. Heydecke G, Butz F, Hussein A, Strub JR. Fracture strength after dynamic loading of endodntically treated teeth restored with different post-and-core systems. J Prosthet Dent 2002; 87: 438-45.

10. Braga RR, Ballester RY, Carrilho MR. Pilot study on the early shear strength of porcelaindentin bonding using dual-cure cements. J Prosthet Dent 1999; 81: 285-9.

11. Braga RR, Cesar PF, Gonzaga CC. Mechanical properties of resin cements with different activation modes. J Oral Rehabil 2002; 29: 257 62.

12. Hahn P, Attin T, Grofke M, Hellwig E. Influence of resin cement viscosity on microleakage of ceramic inlays. Dent Mat 2001; 17: 191-6.

13. Kitasako Y, Burrow MF, Katahira N, Nikaido T, Tagami J. Shear bond strengths of three resin cements to dentine over 3 years in vitro. $\mathrm{J}$ Dent 2001; 29: 139-44.

14. Goracci C, Sadek FT, Monticelli F, Cardoso PEC, Ferrari M. Influence of substrate, shape, and thickness on microtensile specimens' structural integrity and their measured bond strengths. Dent Mat 2004a; 20: 643-54.

15. Goracci C, Tavares AU, Fabianelli A, Monticelli F, Raffaelli O, Cardoso Pde C et al. The adhesion between fiber posts and root canal walls: comparison between microtensile and push-out bond strength measurements. Eur J Oral Sci 2004b; 112:353-61.

16. Hedlund SO, Johansson NG, Sjoren G. Retention of prefabricated and individually cast root canal posts in vitro. Br Dent J 2003; 195 : $155-8$.

17. O’Keefe $\mathrm{KL}$, Miller $\mathrm{BH}$, Powers JM. In vitro tensile bond strength of adhesive cements to new post materials. Int J Prosthodon 2000; 13: 47-51.

18. Sahafi A, Peutzfeldt A, Asmussen E, Gotfredsen $\mathrm{K}$. Bond strength of resin cement to dentin and to surface-treated posts of titanium alloy, glass fibre, and zirconia. J Adhe Dent 2003; 5: 153 62.
19. Sahafi A, Peutzfeldt A, Asmussen E, Gotfredsen $\mathrm{K}$. Retention and failure morphology of prefabricated posts. Int J Prosthodont 2004; 17: 307-12.

20. Perdigão J, Geraldeli S, Lee IK. Push-out bond strengths of tooth-colored posts bonded with different adhesive systems. Am J Dent 2004; 17 : 422-6.

21. Sudsangiam S, Van Noort R. Do dentin bond strength tests serve a useful purpose? J Adhe Dent 1999; 1: 57-67.

22. Ferrari M, Mannocci FA. 'one-bottle' adhesive system for bonding a fibre post into a root canal: an SEM investigation. Dent Mat 2000a; 17: 4229

23. Schwartz RS, Robbins JW. Placement and restoration of endodontically treated teeth: A literature review. J Endod 2004; 30: 289-301.

24. Ferrari M, Vichi A, Mannocci F, Mason PN. Retrospective study of the clinical performance of fiber posts. Am J Dent 2000b; 13: 9-13.

25. Kingsford-Smith SD, Martin FE. Microleakage of glass ionemer/composite restorations: a laboratory study. 1. The influence of glass ionomer cement. Aus Dent J 1992; 37: 23-30.

26. Marco S, Ivanovic C, Elisa M, Maria CC, Marco F. Sealing ability and microscopic aspects of a self-adhesive resin cement used for fiber post luting into root canals. Int Dent SA 2006; 8: 2430 .

27. Luca BP, Giovanni C, Pio B, Massimo G. Adhesive post-endodontic restorations with fiber posts: push-out tests and SEM observations. Dent Mat 2002; 18: 596-602.

28. Andre Luis FS, Vanessa GA, Luis Eduardo SS, Arton AM, Luis Roberto MM. Influence of fiber-post translucency on the degree of conversion of Dual-cured resin cement. J Endodon 2007; 33: 303-5.

29. Carvalho RM, Mendoza JS, Santiago S, Silveira RR, Garcia FC, Tay FR, Pashley DH. Effects of HEMA/solvent combination on bond strength to dentine. J Dent Res 2003; 82; 597 601

30. Leary JM, Holmes DC, Johnson WT. Post and core retention with different cements. Gen Dent 1995; 43(5): 416-9 
31. Ferrari M, Vichi A, Grandini S, Geppi S. Influence of microbrush on efficacy of bonding into root canals. Am J Dent 2002; 15: 227-31.

32. Fernanda Tranchesi Sadek, Cecilia Goracci, Francesca Monticelli, Simone Grandini, Alvaro Hafiz Cury, Franklin Tay, Marco Ferrari. Immediate and 24-Hour evaluation of the interfacial strengths of fiber posts. J Endodon 2006; 32: 1174-7.
33. Goracci C, Sadek FT, Fabianelli A, Tay FRand M, Ferrari M. Evaluation of the adhesion of fiber posts to intraradicular dentin. Oper Dent 2005b; 30: 627-35

34. Bachicha WS, Difiore PM, Miller DA, Lautenschlager EP, Pashley DH. Microleakage of endodontically treated teeth restored with post. J Endo 1998; 24: 703-8. 